\title{
Evaluation of causes of still birth in a tertiary care teaching hospital
}

\author{
Shivani Kothiyal*, Anjoo Agarwal, Vinita Das, Amita Pandey, Smriti Agarwal
}

Department of Obstetrics and Gynecology, King George Medical University, Lucknow, Uttar Pradesh, India

Received: 17 September 2017

Accepted: 20 January 2018

\section{*Correspondence:}

Dr. Shivani Kothiyal,

E-mail: skothiyal40@gmail.com

Copyright: (c) the author(s), publisher and licensee Medip Academy. This is an open-access article distributed under the terms of the Creative Commons Attribution Non-Commercial License, which permits unrestricted non-commercial use, distribution, and reproduction in any medium, provided the original work is properly cited.

\section{ABSTRACT}

Background: Whenever pregnancy occurs there is an expectation that every pregnancy will end with the birth of a healthy baby, yet in a developing country like India 22 in every 1000 births are stillborn. The objective of this study was to evaluate the rate and causes of still birth in a tertiary care teaching hospital, Queen Mary, King George Medical college and university, Lucknow, Uttar Pradesh, India.

Methods: Present study was an observational study in a tertiary care hospital. 7024 births occurred in the institution over a period of 1 year out of which 550 were stillbirths. Stillbirths which weighed over 500 grams were included in the study. After informed consent, details of history about epidemiological factors, obstetric history and medical history were obtained. Antenatal investigations including imaging, delivery details and stillborn morphological characteristics were analyzed to identify the cause of stillbirth

Results: Out of 7024 deliveries, stillbirth rate was 78.30/1000 total births. Cause of intrapartum stillbirth showed statistically significant correlation with patient's place of residence (rural>urban), distance of health centre from her house, time taken to reach first point of contact and her parity. The major obstetrical causes of stillbirth identified were APH $22.36 \%$, hypertensive disorders of pregnancy $19.27 \%$, IUGR $15.27 \%$, unexplained causes $11.09 \%$, malpresentations $9.64 \%$, rupture uterus $9.09 \%$ and obstructed labour $6.36 \%$. Severe anemia was found in $24.91 \%$ as an associated obstetrical cause of stillbirth.

Conclusions: The rate of stillbirth is higher as compared to the Indian data (22/1000 total births). Antepartum obstetric complications (APH, hypertensive disorder of pregnancy, IUGR) were the most common. 15.45\% cases showed intrapartum causes of stillbirth (obstructed labour and rupture uterus) which was significantly higher than developed countries where such cases are negligible. The higher number of intrapartum deaths indicate that better healthcare services can drastically reduce stillbirth rates in developing countries.

Keywords: Rate of stillbirth, Stillbirth, Stillbirth causes

\section{INTRODUCTION}

Whenever pregnancy occurs there is an expectation that every pregnancy will end with the birth of a healthy baby, yet in a developing country like India 22 in every 1000 births are stillborn. ${ }^{1}$ The effect of a stillborn on parents is devastating and long term. Although improvements in maternal care has resulted in a dramatic reduction in stillbirths in high income countries but women in developing countries continue to experience stillbirths at a higher rate. The reason for this disparity usually is due to maternal behaviours, genetics, the physical and social environments and maternal awareness, education and access to and the quality of healthcare. ACOG (American college of obstetricians and gynaecologists) defines stillbirth as a fetal death that occurs during pregnancy at 20 weeks or greater gestation.

For international comparison WHO defines a still born as baby born with no signs of life at or after 28 weeks of 
gestation, with birth weight of 1000 gram or more, or a body length of $35 \mathrm{~cm}$ or more. ${ }^{1}$ In India, there are an estimated 613,500 third trimester still birth every year, with a rate of 22 per 1000 total birth but variation between states is large, with rates of less than 20 per 1000 total birth in Kerala and 66 per 1000 still birth or more in Central India. ${ }^{2,3}$ Worldwide still birth rates has declined by $14 \%$ from 1995 to 2009 resulting in annual decline of $1.1 \%$ per year. But improvement of still birth rate is less in developing countries. ${ }^{4}$

Almost half of still birth happen when women is in labour. Labour and birth are the time of highest risk accounting for an estimated $45 \%$ of the yearly worldwide third trimester stillbirths. ${ }^{5}$ In high income countries, intrapartum stillbirth rates are typically less around $14 \%$ of total third trimester stillbirth, compared with rates of more than $50 \%$ in many countries of south Asia and subSaharan Africa. ${ }^{6,7}$

The rates correlate with access to maternal health care in India. Most stillbirths are seen in un-booked, unsupervised pregnancy, the causes of which may be different from what has been studied in various other developed countries. ${ }^{8}$ In the present study, we study the rate of stillborn at our tertiary care hospital and the various causes of stillborn for a period of 1 year from June 2013 to May 2014 and correlate the various causes of stillbirth with various demographic, social and other causes which lead to stillbirth.

Aims and objectives of the present study was to study the rate and causes of still birth in a Tertiary care teaching hospital.

\section{METHODS}

This study was carried out in Queen Mary Hospital in the Department of Obstetrics and Gynecology, King George's Medical University, Lucknow from June 2013 to May 2014. Hospital allowed both booked, un-booked and emergency cases. During 13 months of study that is from June 2013 to May 2014, 7024 deliveries occurred in the hospital. Out of 7024 deliveries for 550 cases outcome was stillbirth. All women with antenatal, intrapartum stillbirths were included in the study. Out of 550 cases $97.5 \%$ cases already had intrauterine fetal death at admission. All women who were admitted with intrauterine death or had intrapartum death were interviewed after informed consent. Based on the working proforma, detailed history about epidemiological and obstetric details was taken. Detailed examination was done and noted. Working proforma included questions regarding personal information like name, age, husband's age, admission number and date of admission, residential address and whether residing in a rural or urban area, socioeconomic status, religion, height, weight, BMI, literacy of husband and wife, occupation of husband and wife, any history of pre-existing diabetes, history of any previous stillbirths. History of present pregnancy questions included history of smoking if yes then number of cigarettes per day or any passive smoking, history of alcohol intake, history of any medical disorder or any history of taking a non-prescription drug, history of pre conceptional folic acid intake. History of folic acid in first trimester and history of iron/calcium intake. Detailed obstetric history was taken. History of multiple pregnancy, history of previous caesarean section, number time and place of all the antenatal visits were noted.

Questions to assess the geographical remoteness were also asked like distance of nearest health centre, time taken to reach our hospital for referral centre and time taken between onset of problem and reaching our hospital. At time of admission of patient with IUD, LMP and EDD was noted. In case of unknown LMP gestational age was classified in terms of preterm, term and post term. Vitals were taken. Blood pressure with dipstick urine albumin test was done for all patients, detailed general physical and obstetric examination was done. Ultrasounds if available were noted in detail. Details regarding fundal height, liquor assessment, presentation and Fetal heart was noted via obstetric examination. History of bleeding, reduced fetal movements, fever, leaking, foul smelling discharge, trauma and convulsions were asked with leading questions. Time of onset of labour, time of delivery, total duration of labour was noted. NST/CTG records if available was noted. Mode of delivery vaginal or caesarean and indication of caesarean was noted. Delivery details of fetal sex, gestational age at time of death, birth weight, gross congenital anomaly, true knot/false knot of cord and cord around neck was especially looked for.

Stillbirths which weigh more than 500 grams were included in the study. Basic free investigations (Hemogram and HIV and liver function tests) were done in all patients and if any previous blood reports were available was noted. All the history, examination findings, relevant investigation and ultrasound findings was collected and analysed via working proforma and finally complication which lead to stillbirth in this pregnancy was determined based on above details. If no complication was found, then stillbirth was classified under unknown cause (Annexure 1).

\section{RESULTS}

During the period of study, a total of 7024 deliveries took place, out of these 550 were stillbirth. The rate of stillbirth per thousand total births to be $78.30 .^{1-4}$

Mean age of women was $27.28 \pm 5.3$ years. Statistically, association between age and antenatal causes was not significant $(\mathrm{p}=0.380)$. Majority of subjects enrolled in the study were from rural areas $(56.7 \%)$. There were 238 $(43.3 \%)$ women from urban areas. Rural residence was significantly associated with intrapartum causes of stillbirth $(\mathrm{p}<0.001)$ Table $1 .^{9-12}$ 
Table 1: Association of intrapartum causes of stillbirth with place of residence.

\begin{tabular}{|c|c|c|c|c|c|c|}
\hline \multirow{2}{*}{$\begin{array}{l}\text { Place of } \\
\text { residence }\end{array}$} & \multicolumn{2}{|c|}{ Total } & \multicolumn{2}{|c|}{$\begin{array}{l}\text { Intrapartum } \\
\text { causes }\end{array}$} & \multicolumn{2}{|c|}{$\begin{array}{l}\text { Other } \\
\text { causes }\end{array}$} \\
\hline & No. & $\%$ & No. & $\%$ & No. & $\%$ \\
\hline Urban & 238 & 43.3 & 13 & 16.9 & 225 & 47.6 \\
\hline Rural & 312 & 56.7 & 64 & 83.1 & 248 & 52.4 \\
\hline Total & 550 & 100.0 & 77 & 100.0 & 473 & 100.0 \\
\hline
\end{tabular}

Maximum cases had to travel a distance ranging from 6 to $20 \mathrm{~km}(43.6 \%)$ for the purpose of visiting the nearest health care centre followed by those who had to travel 2$5 \mathrm{~km}(28.5 \%)$. A total of 93 women $(16.9 \%)$ had to travel a distance of $21-50 \mathrm{~km}$ and 20 women $(3.6 \%)$ had to travel a distance $>50 \mathrm{~km}$ in order to go to their nearest health facility. Distance $>20 \mathrm{~km}$ was found to be significantly associated with higher proportion of stillbirth cases with intrapartum causes. A total of $36.5 \%$ of women with intrapartum causes had stillbirth as compared to $18 \%$ of women with other causes $(\mathrm{p}=0.002)$ Table 2.

Table 2: Association of intrapartum causes of stillbirth with distance from maternity facility.

\begin{tabular}{|lllllll|}
\hline \multirow{2}{*}{ Distance } & \multicolumn{2}{l}{ Total } & \multicolumn{3}{c|}{$\begin{array}{l}\text { Intrapartum } \\
\text { causes }\end{array}$} & $\begin{array}{l}\text { Other } \\
\text { causes }\end{array}$ \\
\cline { 2 - 8 } & No. & $\%$ & No. & $\%$ & No. & $\%$ \\
\hline$<2 \mathrm{~km}$ & 18 & 3.3 & 0 & 0.0 & 18 & 3.8 \\
\hline $2-5 \mathrm{~km}$ & 157 & 28.5 & 13 & 16.9 & 144 & 30.4 \\
\hline $6-20 \mathrm{~km}$ & 240 & 43.6 & 34 & 44.2 & 206 & 43.6 \\
\hline $21-50 \mathrm{~km}$ & 93 & 16.9 & 23 & 29.9 & 70 & 14.8 \\
\hline$>50 \mathrm{~km}$ & 20 & 3.6 & 5 & 6.5 & 15 & 3.2 \\
\hline $\begin{array}{l}\text { Not } \\
\text { specified }\end{array}$ & 22 & 4.0 & 2 & 2.6 & 20 & 4.2 \\
\hline Total & 550 & 100.0 & 77 & 100.0 & 473 & 100.0 \\
\hline
\end{tabular}

$\chi^{2}=18.547(\mathrm{df}=5) ; \mathrm{p}=0.002(\mathrm{~S})$

Time taken to reach to the first point of contact ranged from $<30 \mathrm{~min}$ to 3 days. Majority of women reached within 3 hours $(66.7 \%)$. There were 105 women $(19.1 \%)$ who reached within 6 to 24 hours. Majority of cases with intrapartum causes reached to facility after $3 \mathrm{hrs}$ as compared to majority of cases with other causes who reached to facility within $3 \mathrm{hrs}$. Statistically, this difference was significant $(\mathrm{p}=0.005)$ Table 3.

Maximum number of women belonged to upper lower class $(45.3 \%)$ followed by those in lower middle class $(38.9 \%)$. A total of $59(10.7 \%)$ women were from lower class. Majority of women were Hindus (79.6\%). There were $20.4 \%$ Muslims. BMI of women ranged from 11.7 to $34.9 \mathrm{~kg} / \mathrm{m}^{2}$. Statistically, the association between BMI and antenatal cause of stillbirth was not significant $(\mathrm{p}=0.658)$. Maximum women were educated to High School $(\mathrm{n}=252 ; 45.8 \%)$ followed by those who were uneducated $(37.1 \%)$. Statistically, the association of causes of stillbirth with education was not significant. ${ }^{13-16}$

Table 3: Association of intrapartum causes with time taken to reach to maternity facility.

\begin{tabular}{|lllllll|}
\hline Time taken & \multicolumn{3}{l}{ Total } & $\begin{array}{l}\text { Intrapar } \\
\text { tum } \\
\text { causes }\end{array}$ & $\begin{array}{l}\text { Other } \\
\text { causes }\end{array}$ \\
& No. & \% & No. & $\%$ & No. & \% \\
\hline <30 min & 91 & 16.5 & 3 & 3.9 & 88 & 18.6 \\
\hline 31 min - 1 hour & 37 & 6.7 & 6 & 7.8 & 31 & 6.6 \\
\hline >1-3 hour & 238 & 43.3 & 30 & 39.0 & 208 & 44.0 \\
\hline >3-6 hour & 73 & 13.3 & 13 & 16.9 & 60 & 12.7 \\
\hline >6-24 hour & 105 & 19.1 & 24 & 31.2 & 81 & 17.1 \\
\hline$>$ 24 hour & 6 & 1.1 & 1 & 1.3 & 5 & 1.1 \\
\hline Total & 550 & 100.0 & 77 & 100.0 & 473 & 100.0 \\
\hline
\end{tabular}

$\chi^{2}=17.000(\mathrm{df}=6) ; \mathrm{p}=0.005(\mathrm{~S})$

Majority of women did not have an antenatal visit to healthcare facility. A total of $112(20.4 \%)$ paid <3 visits, $51(9.3 \%) 3$ visits and $101(18.4 \%)$ paid $>3$ visits. Statistically, there was no significant association between cause and number of antenatal visits. In present study, 449 (81.6\%) were un-booked, while $18.4 \%$ were booked. At our tertiary care hospital among 7074 deliveries, unbooked were $(56.6 \%)$ and booked were 3072 (43.4\%), which shows that in present study, stillbirths were more in un-booked cases.

A total of 30 women $(5.5 \%)$ had associated medical problems. Diabetes $(\mathrm{n}=19 ; 3.5 \%)$ was most common followed by hypothyroidism $(\mathrm{n}=8 ; 1.2 \%)$. Adequate intake of iron and folic acid during pregnancy was reported by $155(28.2 \%)$ while $11(2 \%)$ reported intake but in inadequate quantity during pregnancy. A total of $357(64.9 \%)$ did not report of iron/folic acid intake either during or prior to conception. A total of 122 women $(22.2 \%)$ had hemoglobin levels $>11$ gm\%. Anemia was found in 428 women $(77.81 \%)$

Previous history of stillbirth was reported in 24 (4.4\%) cases. The proportional differences in number of stillbirths between two groups did not result in a statistically significant association with cause of stillbirth in current pregnancy $(\mathrm{p}=0.336)$. Active/passive smoking habit was reported by $10(1.8 \%)$.

Majority of deliveries were preterm deliveries $(n=282$; $51.3 \%$ ). In preterm births, the rate of stillbirth was 172.8 per thousand total births. In term births, the rate was 48.2 per 1000 total births. And in post term the rate of stillbirth was 95.65 per thousand total births.

Maximum number of women were nullipara $(\mathrm{n}=211$; $38.4 \%)$ followed by para $1(23.5 \%)$, para $2(16.5 \%)$, para $3(11.8 \%)$ and para $4(5.6 \%)$ women. A total of $24(4.4 \%)$ women had parity above 4 . Maximum number of women $(\mathrm{n}=241 ; 43.9 \%)$ had no live issues, i.e. they were primipara. The association between parity and antenatal 
causes of stillbirth was not significant statistically $(p=0.677)$. As compared to other causes women with intrapartum causes of stillbirth had significantly higher proportion of women with higher parity (P3 and above) $(\mathrm{p}=0.025){ }^{13,17,18,19}$

Majority had cephalic presentation $(87.7 \%)$. Breech presentation was reported in $46(8.4 \%)$, transverse in 18 (3.3\%), compound in $3(0.5 \%)$ and unstable in $2(0.4 \%)$ women. Proportion of preterm and term deliveries as compared to post-term was higher with cephalic presentation whereas proportion of post-term deliveries as compared to preterm and term deliveries was higher for breech and compound presentation. Transverse presentation was more common in term deliveries as compared to preterm and post-term deliveries. Statistically, association between presentation and term of delivery was significant $(\mathrm{p}=0.006)$.

$97.5 \%$ of cases women came with an Intrauterine dead fetus, 12 had acute fetal distress who eventually died during the intrapartum period and 2 were anomalous. Majority of women had a duration of labour $>12$ hours $(53.1 \%)$. There were 258 women $(46.9 \%)$ having labour duration $<12$ hours.

Vaginal delivery $(\mathrm{n}=334 ; 60.7 \%)$ was most common followed by caesarean delivery $(\mathrm{n}=193 ; 35.1 \%)$. A total of $29(5.3 \%)$ had laparotomy. Majority of foetus were males $(n=331 ; 60.2 \%)$. There were $220(40 \%)$ female. A total of $5(0.9 \%)$ the gender of foetus was ambiguous. There were 4 twin pregnancies. Congenital anomalies were reported in $32(5.8 \%)$ births. Exactly half the babies had birth weight $2.5 \mathrm{~kg}$ or above $(50 \%)$. Birth weight $<1$ $\mathrm{kg}$ was reported in $40(7.3 \%)$, between 1 and $1.499 \mathrm{~kg}$ in $97(17.6 \%)$ and between $1.5-2.499 \mathrm{~kg}$ in $138(25.1 \%)$. HIV positivity was reported in $2(0.4 \%)$. Another two were positive for HBsAg. Raised CRP levels were reported in 19 of chorioamnitis (3.4\%).

APH and preeclampsia were two major complication $(\mathrm{n}=$ $123 ; 22.36 \%$ and $\mathrm{n}=106 ; 19.27 \%$ respectively). ${ }^{20-22} \mathrm{It}$ was observed that preeclampsia was present as the single complication in all the cases where it was diagnosed. APH cases were generally accompanied with one or more other complications too $(71 / 123 ; 57.7 \%)$.

IUGR ( $\mathrm{n}=84 ; 15.27 \%)$, malpresentation $(\mathrm{n}=54$; $9.64 \%)$, rupture uterus $(\mathrm{n}=50 ; 9.09 \%)$ and obstructed labour $(\mathrm{n}=35 ; 6.36 \%)$ were some of the other major complications. ${ }^{21-23}$

Preterm labour $(\mathrm{n}=25 ; 4.55 \%)$, cord prolapse $(\mathrm{n}=17$; $3.09 \%)$, PPROM/PROM ( $\mathrm{n}=15 ; 2.73 \%)$, multiple pregnancy $(\mathrm{n}=14 ; 2.55 \%), \mathrm{Rh}$ negative $(\mathrm{n}=11 ; 2 \%)$ and GDM $(\mathrm{n}=11 ; 2 \%)$ were some relatively less common reasons.

Thyroid disorder, infections, overt diabetes, cholestasis, uterine anomaly, delay in recognition of complications, chronic hypertension, drug intake and dystocia were very rare contributing to less than $2 \%$ of stillbirths. ${ }^{14}$

In $61(11.09 \%)$ the reason could not be specified while 84 $(15.27 \%)$ had reasons other than those cited above Table 4 and 5 .

Table 4: Complications responsible for stillbirth.

\begin{tabular}{|lll|}
\hline Complication & Total & $\%$ \\
\hline Rh negative pregnancy complications & 11 & 2.00 \\
\hline Pre-eclampsia & 106 & 19.27 \\
\hline Chr. HTN & 1 & 0.18 \\
\hline GDM & 11 & 2.00 \\
\hline Overt diabetes & 8 & 1.45 \\
\hline Cholestasis & 8 & 1.45 \\
\hline Thyroid disease & 10 & 1.82 \\
\hline Severe anaemia & 137 & 24.91 \\
\hline Drug intake & 1 & 0.18 \\
\hline Uterine anomaly & 4 & 0.73 \\
\hline Infections & 9 & 1.64 \\
\hline APH & 123 & 22.36 \\
\hline IUGR & 84 & 15.27 \\
\hline Multiple pregnancy & 14 & 2.55 \\
\hline Preterm labour & 25 & 4.55 \\
\hline PPROM/PROM & 15 & 2.73 \\
\hline Malpresentation & 53 & 9.64 \\
\hline Obstructed labour & 35 & 6.36 \\
\hline Rupture uterus & 50 & 9.09 \\
\hline Cord prolapse & 17 & 3.09 \\
\hline Shoulder dystocia & 1 & 0.18 \\
\hline Others & 84 & 15.27 \\
\hline Unexplained & 61 & 11.09 \\
\hline
\end{tabular}

Table 5: Specific causes for cases classified as others.

\begin{tabular}{|ll|}
\hline Cause & No $=84$ \\
\hline Congenital anomaly & 32 \\
\hline Fever & 16 \\
\hline Jaundice & 10 \\
\hline Heart disease in mother (NYHA IV) & 6 \\
\hline Oligohydramnios & 6 \\
\hline H/o fall & 4 \\
\hline CHF (pulmonary oedema with severe & 3 \\
\hline anaemia) & 2 \\
\hline Fever with thrombocytopenia & 1 \\
\hline Polyhydramnios & 1 \\
\hline DIC & 1 \\
\hline Drug reaction & \\
\hline
\end{tabular}

Among the reason cited as Others (total of 84 cases)Congenital anomaly was the most common reason $(\mathrm{n}=$ $32)$ followed by fever $(n=16)$ and jaundice $(n=10)$. A total of 6 had heart disease (NYHA IV) while another 6 had oligohydramnios. History of fall was reported in 4 and $\mathrm{CHF}$ was reported in 3. A total of 2 cases had fever with thrombocytopenia and 1 case each had polyhydramnios, DIC and drug reaction respectively. 


\section{DISCUSSION}

Present study was aimed at evaluating the rate and causes of still birth in a Tertiary care teaching hospital over a period of 1 year from June 2013 to May 2014. In present study at Queen Mary Hospital, total no. of deliveries from June 2013 to May 2014 was 7074. The total number of stillborn was 550. Rate of stillbirth was 78.3/1000 total births (live plus stillborn). ${ }^{1-4}$

Such major difference is first due to lot of under reporting of stillbirths. ${ }^{7}$ The second reason is due to Queen Mary Hospital being a tertiary care hospital, all complicated cases from Lucknow and neighboring areas and sometimes even from neighboring states are coming to the hospital.

In present study cases due to antenatal causes of stillbirth were $415(75.5 \%)$, and intra-partum causes were 77 $(14 \%) .{ }^{24-38}$ In present study majority of subjects enrolled in the study were from rural areas $(56.7 \%)$. There were $238(43.3 \%)$ women who were from urban areas. In present study, rural residence was significantly associated with intrapartum causes of stillbirth $(\mathrm{p}<0.001) .{ }^{9-12}$

Many of the finding in the present study are at variance with reported figures. This is probably due to the large percentage of un-booked and uneducated cases coming to our hospital. Due to this the occurrence of rupture uterus, obstructed labour and eclampsia continues to be high in our hospital. ${ }^{14-17}$ Further strengthening of antenatal and emergency obstetric care services in the rural areas is mandatory to battle with the phenomenally high stillbirth rate. ${ }^{6,7}$

\section{CONCLUSION}

The rate of stillbirth is higher as compared to the Indian data (22/1000 total births). Antepartum obstetric complications (APH, hypertensive disorder of pregnancy, IUGR) were the most common. $15.45 \%$ cases showed intrapartum causes of stillbirth (obstructed labour and rupture uterus) which was significantly higher than developed countries where such cases are negligible.

The higher number of intrapartum deaths indicate that better healthcare services can drastically reduce stillbirth rates in developing countries.

\section{ACKNOWLEDGMENTS}

Authors would like to acknowledge Department of Obstetrics and Gynaecology, King George Medical University, Lucknow, India.

Funding: No funding sources Conflict of interest: None declared

Ethical approval: The study was approved by the Institutional Ethics Committee

\section{REFERENCES}

1. WHO. International statistical classification of diseases and related health problems: tenth revision, volume 2: instruction manual. Geneva: World Health Organization, 1993.

2. Bhutta Z, Nundy S, Abbasi K. Is there hope for South Asia? BMJ. 2004;328:777-8.

3. Bang AT, Bang RA, Baitule SB, Reddy MH, Deshmukh MD. Effect of home-based neonatal care and management of sepsis on neonatal mortality: field trial in rural India. Lancet. 1999;354:1955-61.

4. Cousens S, Blencowe H, Stanton C, Chou D, Ahmed $\mathrm{S}$, Steinhardt L, et al. National, regional, and worldwide estimates of stillbirth rates in 2009 with trends since 1995: a systematic analysis. The Lancet. 2011;377(9774):1319-30.

5. Wang $H$, Yuan $X$, Yan S. Monitoring and intervention of infant mortality rate and fetal and infant mortality rate in Beijing, 1992-2000. Zhonghua Yi Xue Za Zhi. 2001;81:1424-6.

6. Lawn J, Shibuya K, Stein C. No cry at birth: global estimates of intrapartum stillbirths and intrapartumrelated neonatal deaths. Bull World Health Organ. 2005;83:409-17.

7. Maternal and Child Health Research Consortium. Confidential Enquiry into Stillbirths and Deaths in Infancy (CESDI). $7^{\text {th }}$ annual report. London: Maternal and Child Health Research Consortium; 1999.

8. Pattinson R, Kerber K, Buchmann E, Friberg IK, Belizan M, Lansky S, et al. Stillbirths: how can health systems deliver for mothers and babies?. The Lancet. 2011;377(9777):1610-23.

9. Willinger M, Chia-Wen K, Reddy UM. Racial disparities in stillbirth across gestation in united states. Am J Obstet Gynecol. 2009:469:1-8.

10. Akpala CO. Perinatal mortality in a northern Nigerian rural community. J R Soc Health. 1993;113:124-7.

11. Aisien AO, Lawson JO, Okolo A. Two years prospective study of perinatal mortality in Jos, Nigeria. Int J Gynaecol Obstet. 2000;71:171-3.

12. Wu Z, Viisainen K, Wang Y, Hemminki E. Perinatal mortality in rural China: retrospective cohort study. BMJ. 2003;327:1319.

13. Hossain N, Khan NH, Khan N. Obstetric causes of stillbirth at low socioeconomic settings. Acta Obstet Gynecol Scand. 2001;80(3):235-44.

14. Fretts RC. Etiology and prevention of stillbirth. Am J Obstet Gynaecol. 2005;193:1923-35.

15. Luo ZC, Wilkins R, Kramer MS. Effect of neighborhood income and maternal education on birth outcomes: a population-based study. CMAJ. 2006;174:1415-20.

16. Winbo I, Serenius F, Dahlquist G, Källén B. Maternal risk factors for cause-specific stillbirth and neonatal death.al, Acta Obstet Gynecol Scand. 2001;80(3):235-44. 
17. Gordon A, Raynes-Greenow C, McGeechan K, Morris J, Jeffery H. Risk factors for antepartum stillbirth and the influence of maternal age in new South Wales Australia: a population-based study. BMC Pregnancy and Childbirth. 2013;13(1):12.

18. Flenady V, Middleton P, Smith GC, Duke W, Erwich JJ, Yee Kong T, et al. Stillbirth: a way forward in high income countries. Lancet 2011;377:1703-17.

19. Saade, Bukowski, Carpenter, Conway, Dudley, Goldenberg, et al. Association between stillbirth and risk factors known at pregnancy confirmation. JAMA. 2011;306:2469-79.

20. Copper RL, Goldenberg RL, DuBard MB. Risk factors for cause-specific stillbirth and neonatal death. Acta Obstet Gynecol Scand 2001;80:235-44

21. Gardosi J, Madurasinghe V, Williams M, Malik A, Francis A. Maternal and fetal risk factors for stillbirth: population-based study. BMJ. 2013;346:f108.

22. Gardosi J, Kady SM, Mc Geown P, Francis A, Tonks A. Classification of stillbirth by relevant condition at death (ReCoDe); population-based cohort study. BMJ. 2005;331;1113-7.

23. Froen JF, Gardosi JO, Thurmann A, Francis A, Stray-Pedersen B. Restricted fetal growth in sudden intrauterine unexplained deaths. Acta Obstet Gynecol Scand. 2004;83(9):801-7.

24. Froen JF, Arnestad M, Frey K. Risk factors for sudden unexplained death: epidemiological charecteristics in singleton cases in Oslo Norway, 1986-1995. Am J Obstet Gynecol. 2001;184:694702.

25. Ogunyemi D, Jackson U, Buyske S. Clinical and pathologic correlates of stillbirths in a single institution. Acta Obstet Gynecol Scand 1998;77:7228.

26. Huang DY, Usher RH, Kramer MS. Determinants of unexplained antepartum fetal deaths. Obstet Gynecol 2000;95:215-21.

27. Little RE, Weinberg CR. Risk factors for antepartum and intrapartum stillbirth. Am J Epidemiol 1993;137:1177-89.
28. Conde-Agudelo A, Belizan JM, Diaz-Rossello JL. Epidemiology of fetal death in Latin America. Acta Obstet Gynecol Scand. 2000;79:371-8.

29. Myers SA, Ferguson D, Ferguson R. A population study of the relationship between fetal death and altered fetal growth. Obstet Gynecol. 1989;74:32531.

30. Gardosi J, Mul T, Mongelli M. Analysis of birthweight and gestational age in antepartum stillbirths. Br J Obstet Gynaecol. 1998;105:524-30.

31. Smith GCS. Sex, birth weight, and the risk of stillbirth in Scotland, 1980-1996. Am J Epidemiol. 2000;151:614-9.

32. Gruenberger W, Gerstner GJ. The causes of antepartum fetal death: a clinico-pathological study. Clin Exp Obstet Gynecol. 1980;7(4):210-4.

33. Copper RL, Goldenberg RL, DuBard MB, Davis RO. Risk factors for fetal death in white, black, and Hispanic women. Collaborative Group on Preterm Birth Prevention. Obstet Gynecol. 1994;84(4):490-5.

34. Maleckiene L, Nadisauskiene R, Stankeviciene I. A case-referent study on fetal bacteremia and late fetal death of unknown etiology in Lithuania. Acta Obstet Gynecol Scand. 2000;79:1069-74.

35. Raymond EG, Cnattingius S, Kiely JL. Effects of maternal age, parity, and smoking on the risk of stillbirth. Br J Obstet Gynaecol. 1994;101:301-6.

36. Cnattingius S, Bergstrom R, Lipworth L. Prepregnancy weight and risk of adverse pregnancy outcome. N Engl J Med. 1998;338:147-52.

37. Ahlenius I, Thomassen P. The changing panorama of late fetal death in Sweden between 1984 and 1991. Acta Obstet Gynecol Scand. 1999;78:408-14.

38. Kiely JL, Paneth N, Susser M. Fetal death during labor: an epidemiologic indicator of level of obstetric care. Am J Obstet Gynecol. 1985;153:721-7.

Cite this article as: Kothiyal S, Agarwal A, Das V, Pandey A, Agarwal S. Evaluation of causes of still birth in a tertiary care teaching hospital. Int J Reprod Contracept Obstet Gynecol 2018;7:911-6. 